\title{
Photoelastic Analysis of the Vertebral Fixation System Using Different Screws
}

\author{
Photoelastic of the Vertebral Fixation System
}

\begin{abstract}
S. F. Fakhouri
Department of Biomechanics, Medicine and

Rehabilitation of the

Locomotor Apparatus,

Faculty of Medicine of

Ribeirao Preto,

University of Sao Paulo, Brazil

sarahfakhouri@

yahoo.com.br

\author{
M. M. Shimano \\ Department of \\ Mechanical \\ Engineering \\ Triangulo Mineiro \\ mmmshimano@ \\ gmail.com
}

Federal University of

Uberaba, MG, Brazil

Abstract - The purpose of this study was to compare using photoelasticity, the internal stresses produced by two types of pedicular screws (Synthes ${ }^{\mathrm{TM}}$ ) with three different diameters, when submitted to different pullout strengths. The fringe orders were evaluated around the screws using the Tardy compensation method. In all the models analyzed, the shear stress was calculated. Results showed that, independently of the applied load, the screw of smaller outer diameter had larger values of shear stress. According to the analysis realized, we observed that the place of highest stress was in the last thread, close to the head of the screws.
\end{abstract}

\author{
C. A. Araújo \\ Laboratory of \\ Mechanical Projects \\ Professor Henner \\ Alberto Gomide \\ School of Mechanical \\ Engineering of \\ Federal University of \\ Uberlandia, Brazil \\ Cleudmar@ \\ mecanica.ufu.br
}

\author{
H. L. A Defino \\ Department of \\ Biomechanics, \\ Medicine and \\ Rehabilitation of the \\ Locomotor Apparatus \\ Faculty of Medicine \\ of Ribeirao Preto, \\ University of Sao \\ Paulo, Brazil \\ hladefi@fmrp.usp.br
}

\author{
A. C. Shimano \\ Department of \\ Biomechanics, Medicine \\ and Rehabilitation of the \\ Locomotor Apparatus \\ Faculty of Medicine of \\ Ribeirao Preto, \\ University of Sao \\ Paulo, Brazil \\ ashimano@fmrp.usp.br
}

Keywords-photoelasticity; biomechanic, pullout strength, vertebral fixation system

\section{INTRODUCTION}

Resistance to the pullout of the pedicular screws is a value disseminated in the literature and a form of demonstrating, in an objective manner, the screws' resistance to axial load [1-3]. It is one of the most important indices of interest to manufacturers and surgeons [4]. Studies have been carried out by various researchers in order to assess the pullout strength and the factors that may influence it [5-9]. However, studies are usually carried out experimentally without a numerical study related to the strength and specific behavior during the screw pullout being available [10].

Anchorage or support of the fixing systems by means of the screws is of basic importance to the performance of the biomedical functions of the implants applied to the spine. Failure in the stability of the vertebral fixation system may be related to a mechanical failure of the implant or failure in the interface between the bone tissue and the implant [10]. Dislocation of the screw in the bone tissue is a clinical problem commonly seen, caused by the pullout strength [11-12]. Increase in the fixation and stability of the implant requires more pullout strength, reducing the incidence of failure by dislocation of the screw [13-14]. Resistance to the pullout is related to various factors, such as the characteristics of the implants, bone density and insertion torque [4, 8, 15-17]. Bone density is one of the most important factors for the fixation of the screw $[8,18]$.

When pullout strength is applied to the screw, it produces internal stress [19]. Thus, photoelasticity has been used in scientific studies in order to determine the distribution of the stress in structural systems through qualitative and quantitative analysis by means of optical elements [20]. Photoelastic analysis allows for the observation of the distribution of the stress in the whole structure, enabling a general perception of the behavior of the stress [21]. In this technique, the localization of the stress is observed inside an experimental model through fringes of different colorings. It is possible to infer the amount of deformation resulting from a specific strength comparing the stress observed, with the area which is free from stress.

The Optical Stress Law is related to the changes in the index of refraction, due to temporary birefringence, such as the stress state of the material. This relation is expressed in (1) $[22,23]$ :

$$
\sigma 1-\sigma 2=\frac{N \cdot f \sigma}{h}
$$

where:

$f \sigma$ is the optical constant of the material in $\mathrm{N} / \mathrm{mm}$ fringe, $N$ is the order of the fringe, $h$ is the thickness of the model.

The purpose of this study was to determine, analyze and compare the internal stress of photoelastic models under the influence of pedicular screws (USS I and USS II - Synthes ${ }^{\mathrm{TM}}$ ) 
with difference external diameters, when submitted to pullout stress using plane transmission photoelasticity.

\section{MATERIAL AND METHODS}

Pedicular screws of the USS I and USS II system (Synthes ${ }^{\mathrm{TM}}$ ) were used in this study as shown in Figure 1. The USS I type screws are made of stainless steel, and their external diameter is of 5.0, 6.0 and $7.0 \mathrm{~mm}$ (groups G1, G2 and G3, respectively). On the other hand the USS II type screws are made of titanium, and their outer diameter is of 5.2, 6.2 and 7.0 mm (groups G4, G5 and G6, respectively).
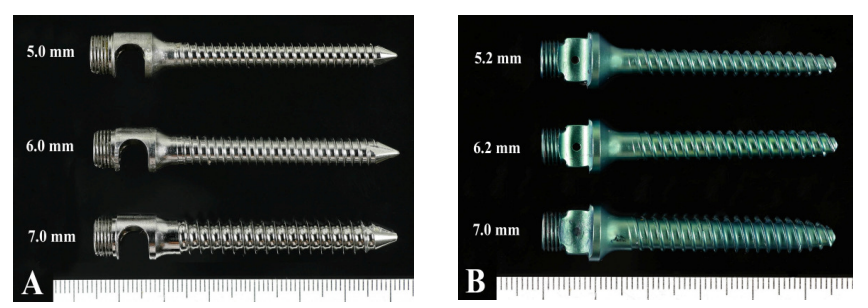

Fig. 1. USS I (A) and USS II (B) vertebral fixation screws (Synthes ${ }^{\mathrm{TM}}$ ).

The photoelastic models were made of flexible photoelastic epoxy resin $\left(\right.$ Polipox $\left.^{\mathrm{TM}}\right)$. This resin has a Young's Modulus of 4.51 MPa and Poisson's Ratio of $0.4 \mathrm{v}$. For the making of these photoelastic models, two standard Teflon ${ }^{\mathrm{TM}}$ moulds (polytetrafluorethylene) were used, as they allow for the reproducibility of the measurements and good finishing surface.

The moulds were sealed using two acrylic plates, one on each side. Between each acrylic plate and the mould, a silicone rubber plate was placed, prepared beforehand, in order for the acrylic plate not to adhere to the photoelastic resin as shown in Figure 2. The whole set was fixed with pressure clamps.

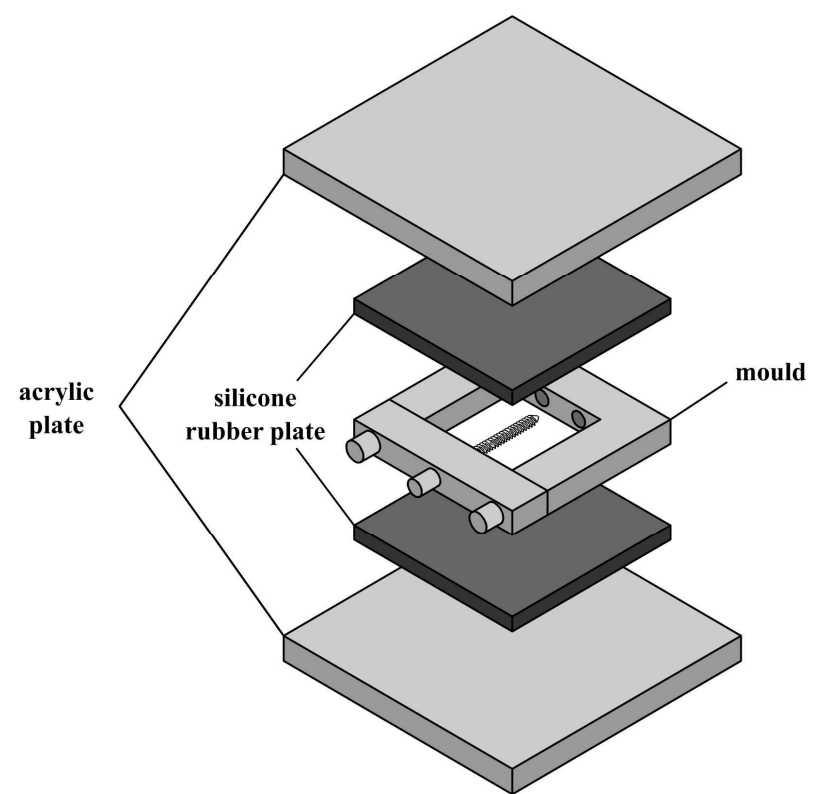

Fig. 2. Schematic of the fabrication of photoelastic epoxy resin models.
The finished model measured $12 \mathrm{~mm}$ in thickness, $51 \mathrm{~mm}$ in width and $58 \mathrm{~mm}$ in length as shown in Figure 3. Twelve photoelastic models were made for the study.

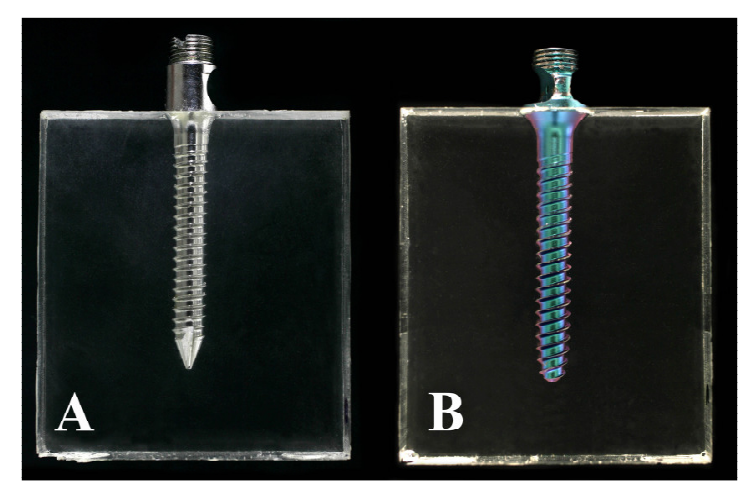

Fig. 3. Photoelastic models with screws type USS I (A) and USS II (B) of 6.0 and $6.2 \mathrm{~mm}$, respectively.

These models were previously submitted to evaluation of the presence of residual stress, called "border effect", before the application of the pullout strength on the screws under analysis. The photoelastic resin showed an optical constant of $0.375 \mathrm{~N} / \mathrm{mm}$ fringe. This value of the constant was used to calculate the shear stress.

\section{A. Photoelastic Analysis}

The photoelastic analysis was carried out on a Transmission Polariscope by means of the application of pullout strength on the screw head, fixed to the photoelastic model. The model was fixed to an adjustable support which was positioned horizontally on the polariscope. A load cell coupled to a signal analyzer was used to measure the stress applied. The stress produced by the screws was assessed qualitatively and quantitatively.

\section{B. Qualitative Analysis}

In the qualitative analysis of the stress, observation was carried out at the starting point of the fringe orders in the model, the point of higher concentration of stress, the point of most sheer stress and the behavior of the stress distribution by means of the application of the different loads.

\section{Quantitative Analysis}

In the quantitative analysis, the sheer stress was measured, using a pullout strength of 1.4, 1.8, 2.4 e $3.3 \mathrm{kgf}$, registered by means of the use of a Kratos ${ }^{\circledR}$ load cell, with a capacity of $10 \mathrm{kgf}$. Notwithstanding the type of the screw, 15 points at $1.5 \mathrm{~mm}$ distance around the contour of the screws were analyzed as shown in Figure 4. The position of the points was standardized for both the USS I and USS II type pedicular screws.

The estimate for the sheer stress $(\tau)$ around the screw was carried out using Tardy's compensation method [22]. The values relating to the optical constant and the thickness of the photoelastic model used in the analysis were $0.375 \mathrm{~N} / \mathrm{mm}$ fringe and $12.0 \mathrm{~mm}$, respectively. 


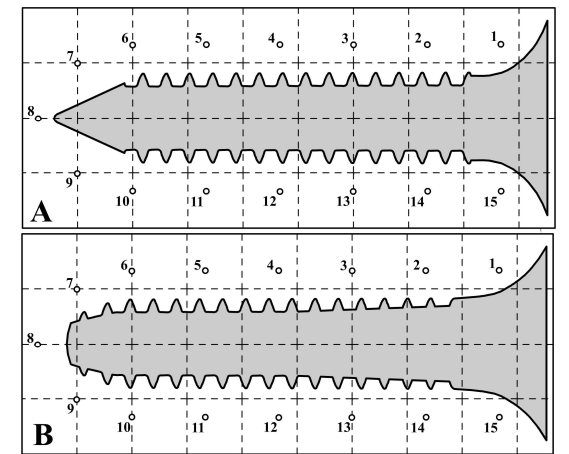

Fig. 4. Schematic of grid used to map showing the fifteen points analyzed in the pedicle screws. (A) USS I; (B) USS II.

\section{RESULTS}

\section{A. Qualitative Analysis}

Qualitative analysis was carried out on the photoelastic moulds correspondent to G1 to G6. In all groups it was possible to observe that the initial point of the fringe orders and the point of higher concentration were on the first threads of the screw, in the region near to the screw heads. Groups G1 to G3 (cylindrical configuration screws) showed higher stress levels on the first threads of the screw than Groups G4 to G6 (conical configuration screws). Concerning the behavior of the stress distribution, it was possible to verify in all groups that the higher the load applied, the bigger the fringe formation along the body of the screw and consequently the bigger the stress in the most critical area (near the screw head) as shown in Figure 5. The results obtained are in accordance with the model, the fixing conditions proposed and the screw dimensions. Thus, as the pullout strength rises, stress gets higher, beginning on the first threads of the screw, located near the screw heads.

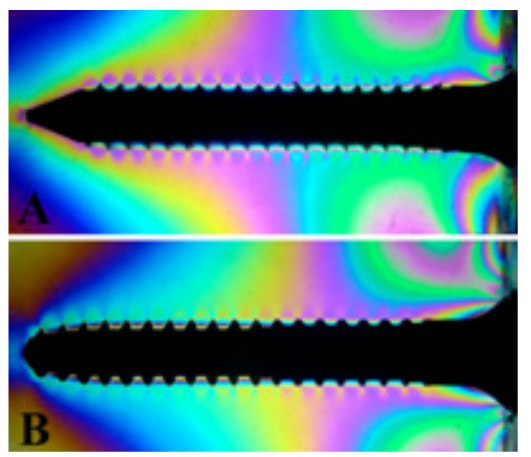

Fig. 5. Pattern of isochromatic fringe orders obtained in the analysis of pedicle screw type USS I (A) and USS II (B) with outer diameter of $6.0 \mathrm{~mm}$ and $6.2 \mathrm{~mm}$, respectively, applying a load of $3.3 \mathrm{kgf}$.

\section{B. Quantitative Analysis}

By means of Tardy's compensation method, the sheer stress $(\tau)$ of the USS I type (groups G1, G2 and G3) and USS II type (groups G4, G5 and G6) pedicular screws were determined, in four load intensities as shown in Table 1.

TABLE I. MEAN \pm STANDARD DEVIATION OF THE SHEAR STRESS OF THE PEDICLE SCREWS TYPE USS I AND USS II IN FOUR LEVELS OF LOADING

\begin{tabular}{c|c|c|c|c|c}
\hline \multicolumn{2}{c|}{ Group } & 1.4 kgf & 1.8 kgf & 2.4 kgf & 3.3kgf \\
\hline & G1 & $13.014 \pm 3.081$ & $16.849 \pm 2.769$ & $21.619 \pm 3.755$ & $27.417 \pm 5.894$ \\
USS I & G2 & $12.360 \pm 3.362$ & $16.696 \pm 3.008$ & $21.413 \pm 3.912$ & $26.810 \pm 5.777$ \\
(KPa) & G3 & $11.505 \pm 2.753$ & $15.366 \pm 3.365$ & $20.403 \pm 3.704$ & $25.470 \pm 6.001$ \\
\hline \multirow{2}{*}{ USS II } & G4 & $9.991 \pm 4.803$ & $14.924 \pm 4.774$ & $19.513 \pm 5.370$ & $25.739 \pm 6.629$ \\
(KPa) & G5 & $9.127 \pm 3.980$ & $13.750 \pm 3.468$ & $18.248 \pm 4.067$ & $23.760 \pm 5.409$ \\
& G6 & $8.810 \pm 3.995$ & $13.249 \pm 3.713$ & $17.896 \pm 3.781$ & $22.764 \pm 4.676$ \\
\hline
\end{tabular}

By means of these tables, it is possible to verify that the averages for the sheer stress of group G1 $>\mathrm{G} 2>\mathrm{G} 3$, notwithstanding the load applied. The same behavior happens when analyzing using the averages of the sheer stress of group G4 > G5 > G6, notwithstanding the value of the load. Group G1 has higher values for general average of sheer stress that group G4, in all the load values applied. The same happens with group G2 and G3 that shows higher average values than group G5 and G6, respectively. Thus we have: G1 > G4, G2 > G5 and G3 > G6.

\section{DISCUSSION}

The photoelasticity technique was discovered at the beginning of the 20th century and its application in the area of Orthopedics and Traumatology is still up to date. This line of experimental research has already got various articles published in this field of study, however, there are no scientific reports using this technique in the analysis of components of the vertebral fixation system.

Photoelasticity has shown itself to be an efficient technique, being able to evaluate in a quick and satisfactory manner the points of higher sheer stress due to the pullout strength. By means of this technique, photoelastic models were made with USS screws cast in the photoelastic resin. These models suggest a simulation of the bone-integrated screw during a chronic post-surgery period, as used in the clinical practice in surgeries with vertebral fixation system. The regular geometry of these photoelastic models allowed the analysis of the screws in vertebral fixation, comparing the outer diameters. In this case, possibly, geometry did not interfere in the results obtained by the photoelastic analysis.

In this study, two types of analyses were carried out, a qualitative and a quantitative one. Photoelasticity was efficient in the qualitative analysis carried out in this study, as it was possible to visualize, satisfactorily, the points of higher sheer stress around the screw, due to the pullout strength. In the general analysis, it was possible to verify that the initial point of the fringe orders and the most critical region was on the first threads of the screw, near the screw head. It is possible to see 
also, that the shape of the fringe orders in the region of the tips of the screws were also different in the USS I and USS II type screws. In the USS I type screws the shape of the fringe was pointed, accompanying their respective geometry; whereas on the USS II type screws, the shape of the fringe was rounded according to their geometry.

In the quantitative analysis, four loads were used in the pullout of the screws $(1.4,1.8,2.4$ and $3.3 \mathrm{kgf})$. For the 1.4 and $1.8 \mathrm{kgf}$ load, the fringe orders formed were smaller, between 0 and 2; with a $2.4 \mathrm{kgf}$ load the fringe orders formed were between 1 and 2 and with the $3.3 \mathrm{kgf}$ load, the fringe orders formed were between 1 and 3 . In this manner, the photoelastic models were analyzed using these four loads in order to observe their behavior due to the increase in the number of fringe orders that appeared with the increase of load, due to the increase in stress on the model. Thus, with the increase of the pullout strength, the sheer stress was more critical, due to which there is an increase in the tendency of the screw to loosen itself. The strength values applied were low, as they served only to generate the pullout strength of the screw, seeing that the photoelastic epoxy resin has high sensitivity. The progressive increase in the strength values applied was important to observe the behavior of the photoelastic model due to the increase in the number of fringe orders. Thus, with the increase in the pullout strength, the sheer stress became more critical and there is a tendency in the loosening of the screw. These conclusions are in accordance with the research carried out by Fakhouri et al. [24].

It is necessary to highlight that the analyses of the stress levels in the models are comparative and that the behavior of the result of the stress on the screw and the bone would be similar, disregarding the effect of the bone geometry. The real load pullout values are higher that the values assessed in the photoelastic models, however the behavior of the result of the stress is similar.

Notwithstanding the value of the load applied, it was possible to verify that the values of the sheer stress in groups G1 and G4 were always higher than groups G2 and G5, which were higher than G3 and G6. When comparing the two types of pedicular screws, the USS II type, correspondent to groups G4 to G6, showed lower values of sheer stress than the USS I type, correspondent to groups G1 to G3, disregarding the measurement of the outer diameter analyzed. Thus, the pedicular screw type USS II showed better stability and resistance to pullout.

The point of the screw which is most susceptible to sheer is the first threads of the screw near the screw head, as it is the point of higher sheer stress. Groups G1 to G3 are more susceptible to sheer, as they show more sheer stress in the first threads of the screw than groups G4 to G6. These results may be explained by the geometrical differences (internal, outer diameter, thread distance and height of the screw thread) and screw dimension.

It was possible to verify that the USS II type screws showed a smaller and more homogeneous formation of fringe orders in the region near to the point than the stress distribution observed in the USS I type screws. Thus, the region near to the point of the USS II type screws showed better stability due to a smaller concentration of stress.

According to the quantitative analyses carried out on the screws with cylindrical configuration, it was possible to verify that the behavior of the $5.0 \mathrm{~mm}$ and the $6.0 \mathrm{~mm}$ screws was the most critical. When applying the same strength, higher rigidity means smaller displacement of the screw. Rigidity depends on the material which is between the threads of the screw, in this case, the photoelastic resin, which has a much lower elasticity module than that of the bone. The $5.0 \mathrm{~mm}$ screw showed a bigger displacement and a smaller rigidity, compared to the 6.0 $\mathrm{mm}$ screw due to the outer and internal diameters of each screw of each screw. However, this difference is not so significant because the height of the screw threads and the distance between the screw threads are the same. This explains the fact that, in the graphs, the behavior of the sheer stress is similar in these screws.

According to Gayet et al. [25], the internal diameter does not have a significant effect in the pullout strength. The bigger the screw thread distance, the smaller the sheer stress between the threads and the bigger the height of the thread, the bigger the pullout strength. Thus, the area between the threads is the point that opposes the pullout of the screw.

The screws with a conical configuration (G4 to G6) offer more anchorage to the vertebra, demanding a higher pullout strength that the cylindrical configuration screws (G1 to G3) $[13,26]$. Conical screws present an increase of $17 \%$ in the pullout strength when compared to the cylindrical screws [13]. However, some authors did not find any difference in the fixation strength of these two types of screws [1, 27]. According to Lill et al. [14], screws with a conical outer design may have inferior properties when compared to the cylindrical ones.

Notwithstanding the type of screw, the smallest outer diameter measurement is the most susceptible to possible clinical intercurrences, according to the dimensions of the screw and due to the fact that it shows a higher sheer stress value. According to Barber et al. [28] and Gayet et al. [25], as the outer diameter of the screw increases, the pullout strength also increases and it becomes more difficult to pull out the screw. Thus, the conclusions obtained in this study are in accordance with these authors. Based on their studies, Kwok et al. [1] affirmed that the pullout strength depends on the outer diameter of the screws. The authors assessed the alterations produced in the pullout strength, based on the outer diameters and they observed that an increase from 5.0 to $6.0 \mathrm{~mm}$ in the outer diameter of the screw produces an increase of $47 \%$ in the pullout strength; an increase from 6.0 to $7.0 \mathrm{~mm}$ in the outer diameter of the screw increases in $65 \%$ its resistance to pullout and this increase reaches $143 \%$, when increasing the outer diameter of the screw from 5.0 to $7.0 \mathrm{~mm}$.

In their study, De Coster et al. [29] conclude that the screw thread has an important role in the pullout strength, in which the smaller and finer thread, even being small, generates a pullout effect. Barber et al. [28] conclude that the performance of the screw is also influenced by its geometrical variation and that as the diameter of the screw increases, the pullout strength 
also increases. The screw displacement before its fail may be related to the screw thread distance, in which its increase will increase the amount of displacement before the fail. The angulation of the screw has little effect on the pullout strength. These findings were the same as those reached in this study.

The results observed in this study show that the higher concentrations of stress generated in the screws with the appliance of pullout strength happened in the first threads of the screw, near the head of the screw, due to the influence of the screw head. This result is in accordance with the study of Daftari et al. [30], which, in studies carried out by means of mechanical pullout trials, observed that the diameter of the pilot hole near the screw head represented the most important point in the anchorage. With these studies, the authors suggest that the entrance point of the screw should be the most precise and tight-fitting as possible.

\section{CONCLUSION}

Photoelasticity showed itself to be an efficient technique, being able to evaluate quickly and satisfactorily the points of higher sheer stress due to pullout strength. In the photoelastic analyses carried out, geometry and the screw dimensions influenced in the results obtained. The pedicular USS II type screw showed lower values of sheer stress than the USS I type, offering more vertebral anchorage and resisting better to pullout strength. Notwithstanding the type of the screw, the one with the smallest outer diameter measurement was, probably, the most susceptible to pullout, as it showed higher values of sheer stress, and due to its geometrical dimensions. In all the analyses carried out, in both types of screws and in the different outer diameter measurements, it was observed that the point of higher concentration of stress was in the first threads of the screw, near the screw head, whatever load was applied.

\section{Acknowledgements}

This research was supported by FAPESP and CAPES.

\section{REFERENCES}

[1] A. W. L. Kwok, J. A. Finkelstein, T. Woodside, T. C. Hearn, R. W. Hu, "Insertional torque and pullout strengths of conical and cylindrical pedicle screw in cadaveric bone", Spine, Vol. 21, No. 21, pp. 24292434, 1996.

[2] M. Pfeiffer, L. G. Gilbertson, V. K. Goel, P. Griss, J. C. Keller, T. C. Ryken, H. E. Hoffman, "Effect of specimen fixation method on pullout tests of pedicle screws", Spine, Vol. 21, No. 9, pp. 1037-1044, 1996.

[3] C. T. Vangsness Jr, D. R. Carter, V. H. Frankel, "In vitro evaluation of the loosening characteristics of self-tapped and non-selftapped cortical bone screws", Clinical Orthopaedics and Related Research, Vol. 157, pp. 279-286, 1981.

[4] Q. H. Zhang, S. H. Tan, S. M. Chou, "Investigation of screw pull-out strength on human spine", Journal of Biomechanics, Vol. 37, No. 4, pp. 479-485, 2004.

[5] T. Hirano, K. Hasegawa, H. E. Takahashi, U. Seiji, H. Toshiaki, W. Toshikatsu, S. Toru, Y. Motoo, I. Masayuki, "Structural characteristics of the pedicle and its role in screw stability", Spine, Vol. 22, No. 21, pp. 2504-2509, 1997.

[6] T. H. Lim, H. S. An, C. Evanich, K. Y. Hasanoglu, L. McGrady, C. R. Wilson, "Strength of anterior vertebral screw fixation in relationship to bone mineral density", Journal of Spinal Disorders, Vol. 8, No. 2, pp. 121-125, 1995.
[7] B. S. Myers, P. J. Belmont Jr, W. J. Richardson, J. R. Yu, K. D. Harper, R. W. Nightingale, "The role of imaging and in situ biomechanical testing in assessing pedicle screw pull-out strength", Spine, Vol. 21, No. 17, pp. 1962-1968, 1996.

[8] M. R. Zindrick, L. L. Wiltse, E. H. Widell, "A biomechanical study of intrapedicular screw fixation in the lumbar spine", Clinical Orthopaedics and Related Research, Vol. 203, pp. 99-112, 1986.

[9] P. M. Zink, "Performance of ventral spondylodesis screws in cervical vertebrae of varying bone mineral density", Spine, Vol. 21, No. 1, pp. 45-52, 1996.

[10] M. Law, A. F. Tencer, P. A. Anderson, "Caudo-cephalad loading of pedicle screw: mechanisms of loosening and methods of augmentation", Spine, Vol. 18, pp. 2438-2443, 1993.

[11] A. Alobaid, V. Arlet, A. Busato, T. Steffen, "Pull-out strength of the suprapedicle claw construct: a biomechanical study", European Spine Journal, Vol. 14, No. 8, pp. 759-764, 2005.

[12] C. C. Hsu, C. K. Chao, J. L. Wang, S. M. Hou, Y. T. Tsai, J. Lin, "Increase of pullout strength of spinal pedicle screws with conical core: biomechanical tests and finite element analyses", Journal of Orthopaedic Research, Vol. 23, pp. 788-794, 2005.

[13] B. B. Abshire, R. F. McLain, A. Valdevit, H. E. Kambic, "Characteristics of pullout failure in conical and cylindrical pedicle screws after full insertion and back-out", Spine, Vol. 1, pp. 408-414, 2001.

[14] C. A. Lill, E. Schneider, J. Goldhahn, A. Haslemann, F. Zeifang, "Mechanical performance of cylindrical and dual core pedicle screws in calf and human vertebrae", Archives of orthopaedic and trauma surgery, Vol. 126, No. 10, pp. 686-694, 2006.

[15] D. W. Bühler, U. Berlemann, T. R. Oxland, N. Lutz-Peter, "Moments and forces during pedicle screw insertion: in vitro and in vivo measurements", Spine, Vol. 23, No. 11, pp. 1220-1227, 1998.

[16] S. D. Cook, S. L. Salkeld, T. Stanley, A. Faciane, S. D. Miller, "Biomechanical study of pedicle screw fixation in severely osteoporotic bone", Spine journal, Vol. 4, No. 4, pp. 402-408, 2004.

[17] S. Eggli, "Biomechanical testing of three newly developed transpedicular multisegmental fixation systems", European Spine Journal, Vol. 1, No. 2, pp. 109-116, 1992.

[18] S. Soshi, R. Shiba, H. Kondo, K. Murota, "An experimental study on transpedicular screw fixation in relation to osteoporosis of the lumbar spine", Spine, Vol. 16, No. 11, pp. 1335-1341, 1991.

[19] J. D. Coe, "Influence of bone mineral density on the fixation of thoracolumbar implants: a comparative study of transpedicular screws, laminar hooks, and spinous process wires", Spine, Vol. 15, No. 9, pp. 902-907, 1990.

[20] D. B. Mahler, F. A. Peyton, "Photoelasticity as a research technique for analyzing stresses in dental structures", Journal of Dental Research, Vol. 34, No. 6, pp. 831-838, 1955.

[21] A. R. Mac Gregor, T. P. G. Miller, J. W. Farah, "Stress analysis of partial dentures", Journal of Dentistry, Vol. 6, No. 2, pp. 125-132, 1978.

[22] J. W. Dally, W. F. Riley, "Experimental stress analysis", 1991, $3^{\text {a }}$ ed. Nova York: Mcgraw-Hill.

[23] Y. Okada, S. Ikeda, T. Fukuda, F. Arai, M. Negoro, I. Takahashi, "Photoelastic Stress Analysis on Patient-Specific Anatomical Model of Cerebral Artery", Proceeding of the Symposium on MicroNanoMechatronics and Human Science, pp. 538-543, 2007.

[24] S. F. Fakhouri, C. A. Araujo, A. Zamarioli, E. Timóteo, A. C. Shimano, "Analysis of compressive distributional load of intervertebral disc L4-L5 meand of photoelasticity", Fiep Bulletin, Vol. 79, pp. 21-23, 2009.

[25] L. E. Gayet, P. Pries, H. Hamcha, J. P. Clarac, J. Texereau, "Biomechanical study and digital modeling of traction resistance in posterior thoracic implants", Spine, Vol. 27, pp. 707-714, 2002.

[26] A. Ono, M. D. Brown, L. L. Latta, E. L. Milne, D. C. Holmes, "Triangulated pedicle screw construct technique and pull-out strength of conical and cylindrical screws", Journal of spinal disorders, Vol. 14, No. 4, pp. 323-329, 2001. 
[27] S. Inceoglu, L. Ferrara, R. F. McLan, "Pedicle screw fixation strength: pullout versus insertional torque", Spine, Vol. 4, No. 5, pp. 513-518, 2004.

[28] J. W. Barber, S. D. Boden, T. Ganey, W. C. Hutton, "Biomechanical study of lumbar pedicle screws: does convergence affect axial pullout strength?", Journal of Spinal Disorders, Vol. 11, No. 3, pp. 215-220, 1998.

[29] T. A. De Coster, D. B. Heetderks, D. J. Downey, J. S. Ferries, W. Jones, "Optimizing bone screw pullout force", Journal of Orthopaedic Trauma, Vol. 4, No. 2, pp. 169-174, 1990.

[30] T. K. Daftari, W. C. Horton, W. C. Hutton, "Correlations between screw hole preparation, torque of insertion, and pullout strength for spinal screws", Journal of Spinal Disorders, Vol. 7, No. 2, pp. 139-145, 1994. 